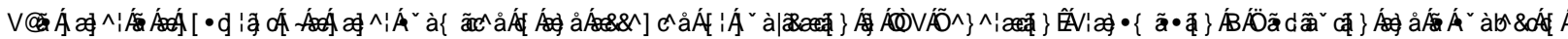

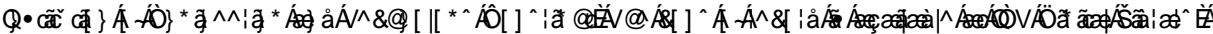

\title{
Distribution Network Reconfiguration Validation with Uncertain Loads - Network Configuration Determination and Application
}

\author{
X Bai ${ }^{1}$, Y Mavrocostanti ${ }^{2}$, D Strickland ${ }^{1 *}$, C Harrap $^{2}$ \\ ${ }^{1}$ Aston University, Birmingham Triangle, Birmingham, UK \\ ${ }^{2}$ Western Power Distribution, Pegasus Business Park, East Midlands, UK \\ d.strickland@aston.ac.uk
}

\begin{abstract}
Automatic load transfer (ALT) on the $11 \mathrm{kV}$ network is the process by which circuit breakers on the network are switched to form open points in order to feed load from different primary substations. Some of the potential benefits that may be gained from dynamically using ALT include maximising utilisation of existing assets, voltage regulation and reduced losses. One of the key issues, that has yet to be properly addressed in published research, is how to validate that the modelled benefits really exist. On an $11 \mathrm{kV}$ distribution network where the load is continually changing and the load on each distribution substation is unlikely to be monitored - reduction in losses from moving the normally open point is particularly difficult to prove. This paper proposes a method to overcome this problem and uses measured primary feeder data from two parts of the Western Power Distribution 11kV Network under different configurations. The process of choosing the different configurations is based on a heuristic modelling method of locating minimum voltages to help reduce losses.
\end{abstract}

\section{Introduction}

The cost and limited flexibility of traditional approaches to $11 \mathrm{kV}$ network reinforcement threaten to constrain the uptake of low carbon technologies. In the UK, to enable Distribution Network Operators (DNOs) to develop new approaches, OFGEM (Office of Gas and Electricity Markets, a UK National Regulatory Authority) has released $£ 500$ m of funding - Low Carbon Network Fund (LCNF) [1] for DNOs to trial innovative techniques and share the learning with the rest of the industry. Project FALCON [2] was funded via this OFGEM initiative to DNO Western Power Distribution plc. (WPD), and aimed to facilitate the uptake of low carbon technologies by delivering faster and cheaper connections to the $11 \mathrm{kV}$ network by reducing traditional reinforcement requirements. The trial provided learning on the use of real time data to inform network planning rather than traditional indicators such as total demand and engineering guidelines.

Automatic load transfer (ALT) on the $11 \mathrm{kV}$ network is the process by which circuit breakers on the network are switched to form open points in order to feed load from different primary substations. Some of the potential benefits that may be gained from dynamically using ALT include maximising utilisation of existing assets, voltage regulation and reduced losses.

The implementation of ALT depends on the network configuration and connected load. Network reconfiguration is a highly complex, non-differentiable, constrained, non-linear (due to the on-off nature of 
the circuit breakers) mixed integer optimization problem, due to the high number of switching elements in a distribution network. The number of possible configurations on a distribution system is related to the number of switch state combinations, which increases in a factorial relation with the number of switches existing in the network. Thus, evaluation of all possible configurations is time consuming. The process of choosing the optimal configuration of open points for a variety of different benefits has been studied by many researchers for many years.

From a theoretical perspective, a network reconfiguration is an optimisation problem which may have different objective functions, such as minimum switching operations, minimum power loss, balanced feeder load balancing, or their combination [3-9] to comply with a set of operational constraints such as bus bar voltage limits, line or cable capacity ratings and fault levels. Generally these methods can be grouped into several categories; classic optimization technique [10-13], sensitivities analysis method [14], knowledge-based heuristic method [15-18], and Genetic Algorithms [19]. Sensitivities analysis method and knowledge-based heuristic method can provide practical results with short computing time but may not be global solutions. Heuristic techniques can be further classified as "Sequential Switch Opening" $[20,21]$ and "Branch Exchange" [22,23].

There are a number of issues with the research published in this area;

1. The ALT method chosen needs to be used in conjunction with a network. Some authors have used small test networks such as the IEEE 33 or IEEE70 Bus bar model. The advantage of this type of approach is that different methods of finding the optimal normal open points can be compared easily and because of the prescribed nature of the network the results are repeatable by other researchers. The disadvantage is that only theoretical benefits are obtained and it is not apparent if the advantages claimed can make the transition to a real world situation. Some of this research along with other research has used models of sections of Distribution Networks. Using real network data gives a better picture of how the method may be applied to a real life situation, however, it is not always clear what the quality of the data is behind the model. In particular, the load data in a distribution network is rarely monitored in detail at secondary transformer level and therefore a measured value of primary load current is typically divided among the distribution substations based on indicators such as secondary transformer maximum demand indication. This results in a single case of load division between substations with time - which is not representative of a real network where the load at different substations changes with respect to each other over time. The consequence is that this leads to a single representation of the optimum position of the open points. Where the authors have looked at time varying loads, stochastic evaluation with considering of load uncertainties and load partition with seasonal variation are used. 
2. Once the optimum location of the open points has been found, it is necessary to validate that the method behind the locations produces the claimed benefits. Within small test networks this typically manifests itself as an academic study, looking at say improvements in losses, between different configurations. For a Network study, the majority of researchers look at theoretical benefits by comparing calculated parameters under different configurations. Measured validation on a Network is difficult to achieve in practice because the load is continually varying and the load prior to changing the configuration may be different to load after changing the configuration making it difficult to look at claimed benefits, such as loss reduction, directly between different network configurations.

This paper is significantly different from previously published literature in this area because it looks at the process behind how benefits can be validated using measured network data on a practical scale taking into account the issue of substation time varying loading and uncertainty. Section 2 of this paper summarizes the network. Section 3 looks at how a set of new normally open points were derived in the face of load distribution uncertainty and calculates the benefits under different configurations. Section 4 describes the methodology for model validation. Section 5 explains the experimental network data and trial configurations. Section 6 illustrates the benefits of the trial operation and the conclusions are drawn in Section 7.

\section{Network}

Two representative trial networks are taken from Milton Keynes area, based on a Cable and OHL network. The Cable network is fed via two primary $33 / 11 \mathrm{kV}$ substations with a total of seven feeders from Newport Pagnell and Marlborough Street substations. The network includes 137 buses and 143 branches and the simplified schematic is shown in Fig. 1 . The OHL network is fed via two primary $33 / 11 \mathrm{kV}$ substations with a total of five feeders from Newton Road and Winslow substations. The network includes 266 buses and 269 branches and the simplified schematic is shown in Fig.2.

Data on the Network cabling was provided by WPD and cross checked against the Network Design Manual and a Graphic Information System (GIS). The distribution substations load profiles were provided from a proprietary WPD based model, which used low voltage load monitoring data from various substation types to developed statistical models of loads at each substation. The load profiles at each $11 \mathrm{kV}$ substation were derived from the statistical models giving load in 48 half-hourly periods of each day of a year. The results of the load profiling were cross checked against static indicators including maximum demand indicators and the winter max at each substation and scaled to the total measured feeder demand. 


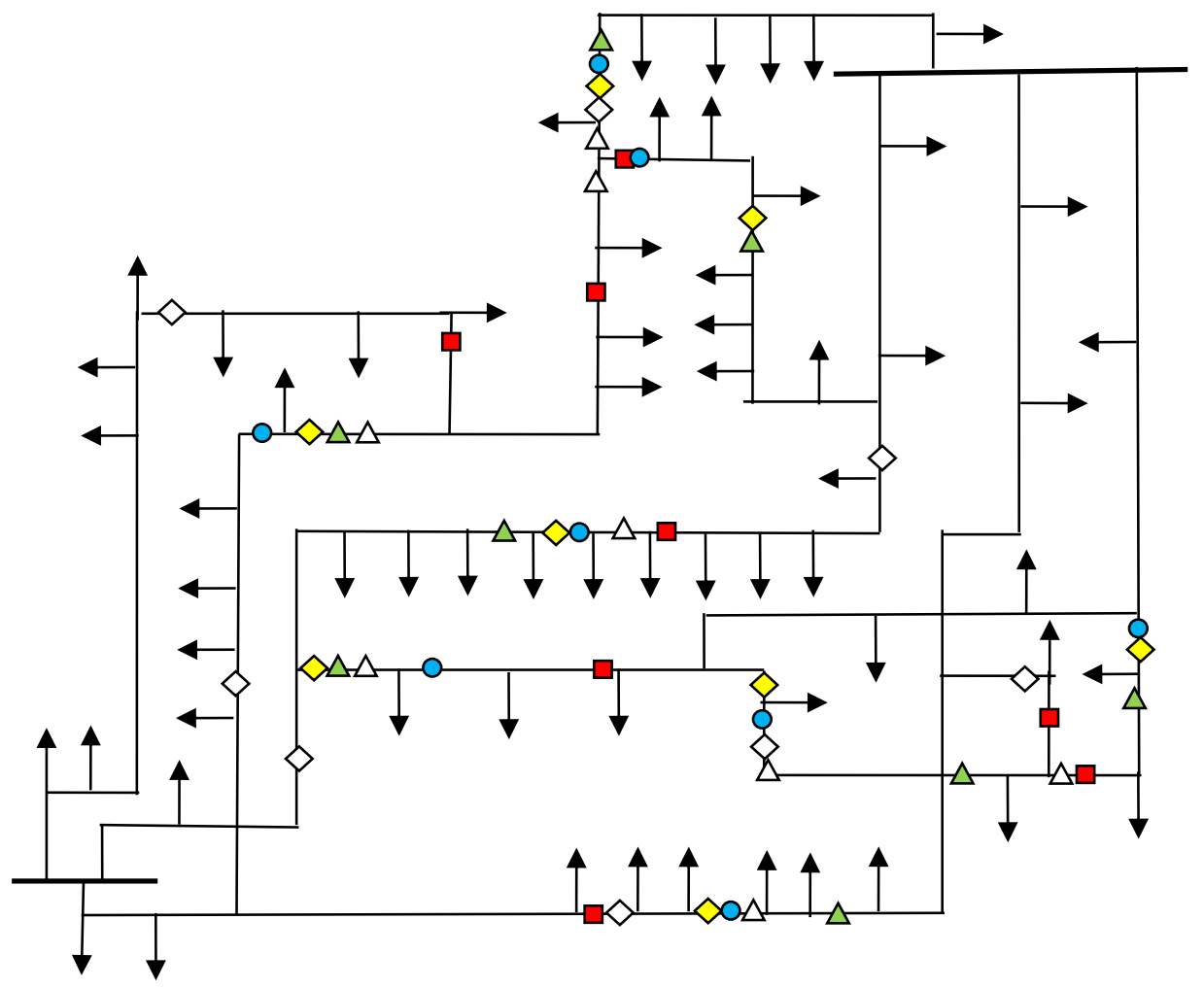

$\square$ Nominal $\Delta$ Configuration1 $\diamond$ Configuration2 $\bigcirc$ Min Voltage $\Delta$ Monte-Carlo $\diamond$ Customer balance

Fig.1 Simplified schematic of Cable trial network showing open points

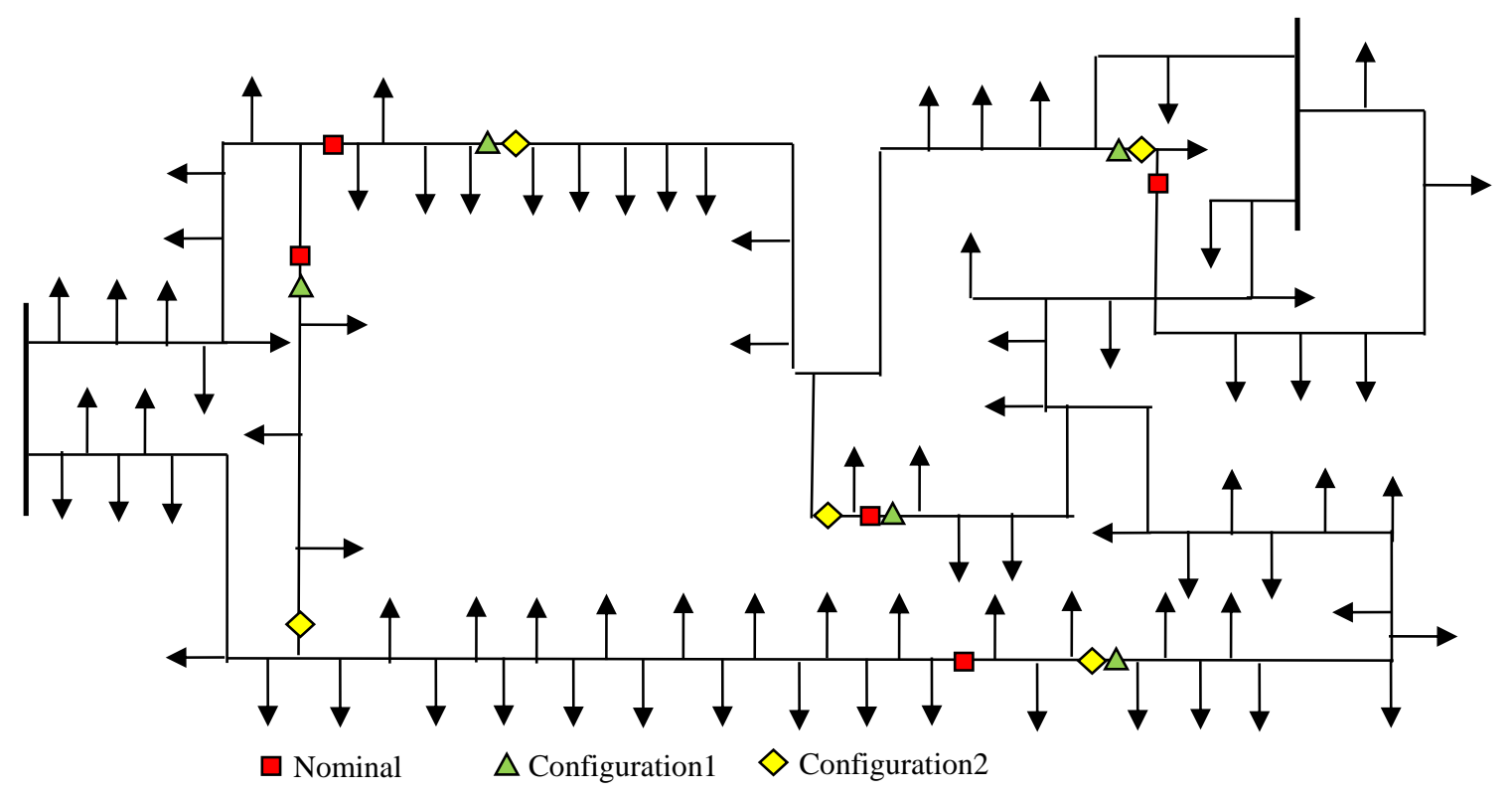

Fig.2 Simplified schematic of OHL trial network showing open points

Only current was measured as feeder demand at the primary substation in Amps in half hour portions. Therefore, values of power factor and voltage were unknown and representative values chosen following 
discussions with the network operator. The power factor at each substation was assumed to be 0.95 and the voltage at the primary substation is assumed to be $11.3 \mathrm{kV}$. Customer numbers were identified from reports to OFGEM on customer interruptions and compared to the 2011 MPAN count. All ambiguous data was corrected to produce the best quality model representation of the Network possible.

\section{Network re-configuration and benefits}

\subsection{Network Re-configuration Process}

A multi-stage process for determining a network re-configuration for implementation in the trial network was used. The main focus of this work was to understand how to experimentally validate the modelled benefits so a heuristic approach to network re-configuration was taken to allow a straightforward approach.

- Different heuristic methods of determining network configuration were used at peak load and minimum load to decide on a method which allowed a good compromise between additional gains in network capacity and loss reduction against the number of customers which would be affected in the event of a fault.

- A heuristic method was used with a Monte-Carlo approach to load distribution to understand the implications of distribution uncertainty on the location of the open points in the network configuration.

- Normally open points from analysis in conjunction with network switching practicalities were used to choose the locations for open point configuration implementation within the trial network.

The methods used for comparison under the project were;

1. Sequential switch opening (common existing method of NOP determination)

2. Heuristic method of opening normally open points based on minimum voltage based on a single load flow solution similar to sequential switching (described below)

3. Heuristic method of opening normally open points based on minimum power flow based on a single load flow solution similar to sequential switching

4. Customer numbers balancing method with tree search.

The results for the sequential switching (1) and the heuristic method of opening normally open points based on minimum power (3) were identical, so only three sets of results are given. The Cable Network comparison was completed first. On the basis of the results from this and to ensure consistency of 
methodology only the minimum voltage method (2) and customer number balancing method (4) were used on the Overhead Line Network to help with time constraints.

Sequential Switch Opening is the process where all the switches of the network are initially closed forming a meshed network, then, to eliminate network loops, the switches are opened sequentially starting with the switch that has the lowest branch power. The process deals with a branch at a time and is repeated until the network reaches a radial structure. An adaptation of the sequential switch opening method based on minimum substation voltage was used to identify the locations of the normal open points (NOP) for network reconfiguration as shown in Fig.3. The network model is meshed and a load flow study using a commercial load flow package (IPSA) was run. The points on the network with the lowest independent voltage are identified (the line impedance is used to indicate which side of the substation the breaker should be opened). Once the correct numbers of open points have been identified (so there are no meshes within the network) these become the basis for the new ALT configuration. The difference between this method and the sequentially switched method are that the points are all identified from one load flow solution (as opposed to sequential solutions). If the study were undertaken on a one-by-one basis, the procedures of opening a point may well distort the power flow and result in a different set of solutions. Absolute values of voltage were used and therefore, to ensure independence, substations and lines next to newly identified normally open points were ignored in the analysis because these are not independent. Connections that resulted in substations with no power, lines overloaded, or voltage limits exceeded were not allowed.

Dividing customer numbers along each feeder equally by using a search tree method to re-configure the networks was also used by way of comparison. The methods of determining network configuration were undertaken at peak load and minimum load to help decide on a method of open point determination for use in the trial which allowed a good compromise between additional gains in network capacity and loss reduction against the number of customers which would be affected in the event of a fault. Meanwhile, 


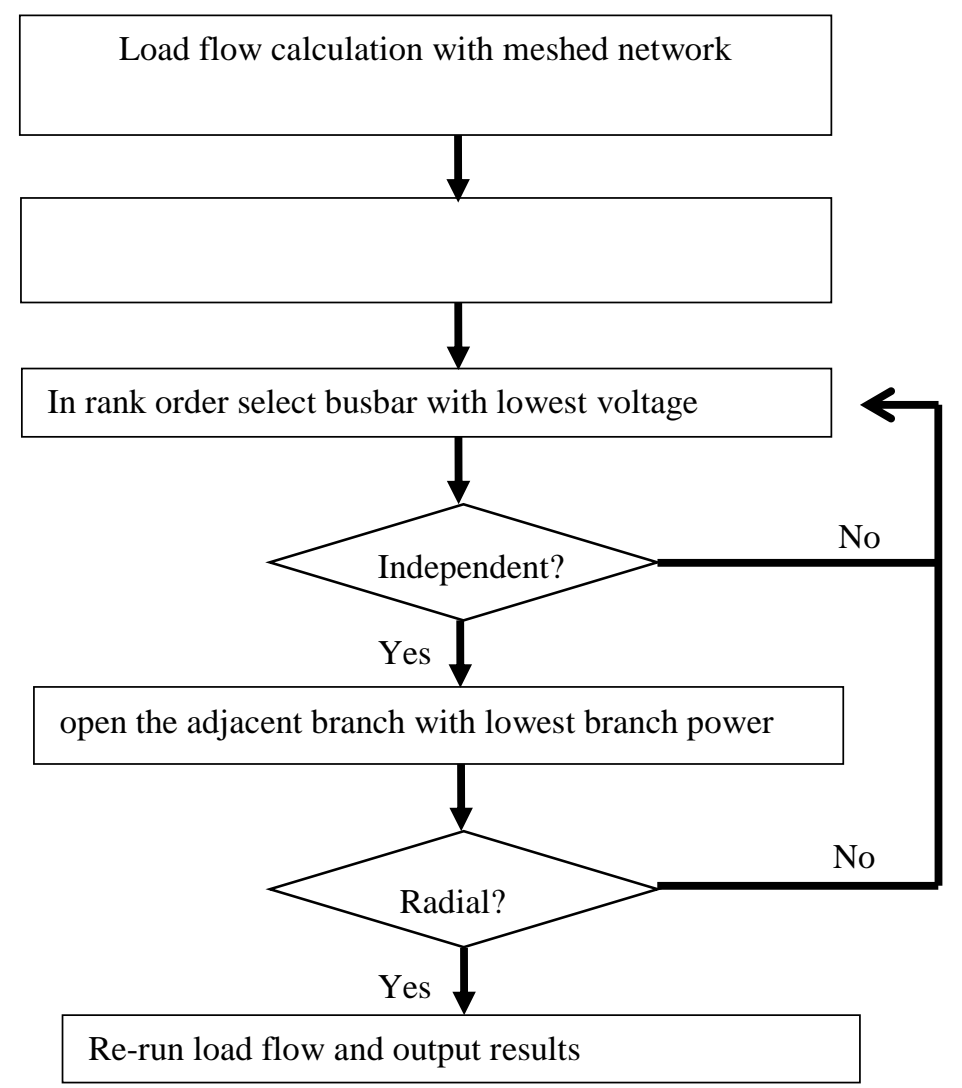

Fig.3 Flow chart of NOP determination with minimal nodal voltage

\subsection{Modelled Benefits}

Benefits in Network re-configuration can be obtained from the load flow solutions of the Network in its resultant configurations. Losses along the cables, voltage at the substation, cable loading, changes to fault levels, effect of outages and peak numbers of customers lost in the event of a fault were all calculated and compared. No noticeable effect on fault levels was calculated. The results for some of the other benefits at both peak load and minimum load condition using heuristic re-configurations are shown in Table 1 and Table 2.

Table 1 Cable Network - benefits calculated by different heuristic methods of determining open points

\begin{tabular}{cccccc}
\hline Load & Heuristic routine & $\begin{array}{c}\text { Losses over } \\
\text { 30min time } \\
\text { span(kWh) }\end{array}$ & $\begin{array}{c}\text { Vmin } \\
(\mathrm{kV})\end{array}$ & $\begin{array}{c}\text { Max Cable Loading } \\
(\%)\end{array}$ & $\begin{array}{c}\text { Max CI in the event of } \\
\text { a fault }(\%)\end{array}$ \\
\hline Peak & Nominal NOPs & 49.7 & 11.14 & 43.0 & 26.1 \\
Peak & Sequential Switching & 47.3 & 11.14 & 40.8 & 33.7 \\
Peak & Min node voltage & 44.8 & 11.15 & 37.3 & 30.8
\end{tabular}




$\begin{array}{lccccc}\text { Peak } & \text { Customer No. Bal } & 65.7 & 11.09 & 76.2 & 17.6 \\ \text { Min } & \text { Nominal NOPs } & 7.4 & 11.22 & 17.4 & 26.1 \\ \text { Min } & \text { Sequential Switching } & 7.7 & 11.23 & 19.2 & 34.0 \\ \text { Min } & \text { Min node voltage } & 6.7 & 11.23 & 16.4 & 22.8 \\ \text { Min } & \text { Customer No. Bal } & 9.7 & 11.22 & 30.9 & 17.6\end{array}$

Table 2 OHL Network -benefits calculated by different heuristic methods of determining open points

\begin{tabular}{cccccc}
\hline Load & Heuristic routine & $\begin{array}{c}\text { Losses over 30min } \\
\text { time span(kWh) }\end{array}$ & $\begin{array}{c}\text { Vmin } \\
(\mathrm{kV})\end{array}$ & $\begin{array}{c}\text { Max Cable Loading } \\
(\%)\end{array}$ & $\begin{array}{c}\text { Max CI in the event of } \\
\text { a fault }(\%)\end{array}$ \\
\hline Peak & Nominal NOPs & 29.3 & 11.08 & 51.4 & 30.8 \\
Peak & Min Node voltage & 25.0 & 11.02 & 55.2 & 29.0 \\
Peak & Customer No Bal & 34.1 & 10.97 & 51.2 & 21.0 \\
Min & Nominal NOPs & 4.2 & 11.12 & 20.1 & 30.8 \\
Min & Min Node voltage & 3.1 & 11.18 & 16.0 & 32.0 \\
Min & Customer No Bal & 4.3 & 11.13 & 20.1 & 21.0
\end{tabular}

Changing the open point configuration can have a number of impacts;

1. There is very little impact on the minimum voltage no matter which method of determining the NOP point is used.

2. Using customer numbers to distribute the load results in a greater imbalance on the feeders as shown in Tables 1 and 2. This impacts the losses and \% capacity used which are both higher than the base case. However, the number of customers on each feeder is more balanced.

3. Using power flow and voltage to set the location of the normally open points allows the losses to be reduced and the maximum circuit loading to be reduced compared to the base case.

4. Savings of up to $6 \%$ in capacity usage in Cable network can be made at peak load by changing the NOP configuration.

5. Using voltage to determine the location of the NOP is slightly better than using the power flow or sequential switching. The difference between the configurations of NOP found using the voltage method at minimum and peak load are only minimally different, which means that the proposed method is appropriate as a way of determining open point over the range of loads likely to be encountered on the Network. An additional advantage to the voltage method is an improvement in the ease with which circuits can be back fed in the event of an outage.

6. The gain in losses and capacity are made at the cost of customer distribution on each feeder. A more unbalanced loading could affect the CI and CML figures as a fault could take out a higher \% of customers at one time.

It is worth noting that higher losses are accompanied with higher cable loading in the Cable network (comparing nominal and minimum voltage rows). However, in the OHL network, the customers are more 
rural and have much lower loads towards where the NOP is located so higher overhead line loading is not so intrinsically linked to a gain in losses due to the low power flow at the end of each feeder. The max feeder loading and voltage drop is more pronounced when customer numbers are used to split the network.

\subsection{Taking into account load distribution uncertainty}

One of the big issues with calculating open points and network re-configuration is the uncertainty in the load distribution within the secondary transformers and the time varying nature of this. A Monte-Carlo analysis was used on Cable network with proposed minimal nodal voltage method to look at the impact of statistically varying the load distribution and its impact using the proposed heuristic voltage method at peak load condition to understand the variability in the open point location.

To undertake this, the total load at all the feeders was summed together and then randomly distributed around all the loads in the network (repeated 1000 times). The location of the NOP's was determined and these were then plotted as a frequency plot (function of how many times) the open points were identified as being the location with the minimum voltage. The eight most common points are plotted in Fig. 1 along with the location of the nominal open points and those found from the voltage method and by considering equal customer numbers.

\section{Model Validation Process}

The networks were re-configured based on the theoretical establishment of the open points however it is not yet clear whether the change in open points offers any practical benefits and how this can be proven especially under varying load. Fig. 4 shows the network model validation process that was used to try and prove that a gain in benefits exists on the trial networks. The flow of data can be summarised as follows:

a. Over a week long period, each proposed NOP configuration was deployed and the half hourly feeder currents were recorded.

b. As far as possible - the model and load profile was validated by using the difference in feeder currents for each configuration and comparing to the recorded currents. This is shown separately in Fig. 5 because of the complexity of the process. There is a lack of monitoring on each $11 \mathrm{kV}$ distribution substation (for simplicity, the distribution substation will be referred to as substation for the rest of the paper) and as such there is uncertainty around how the load is distributed along the feeders. In an ideal scenario the load profile on each feeder would be both accurate and identical for each timeslot in the week such that the measured feeder currents would always match the calculated feeder currents over a week period for a fixed configuration. While looking at different configurations, changes in total current in the 
feeders would be dependent on the losses in each network due to different configuration and as such a better configured network would have lower losses and the feeder current would be lower. However, the load is not fixed in time but is varying. So, instead of looking at absolute values of feeder currents, it is necessary to look at the ratio of total currents for different configurations.

c. Once the model is validated, the benefits of each network configuration can be compared through modelling.

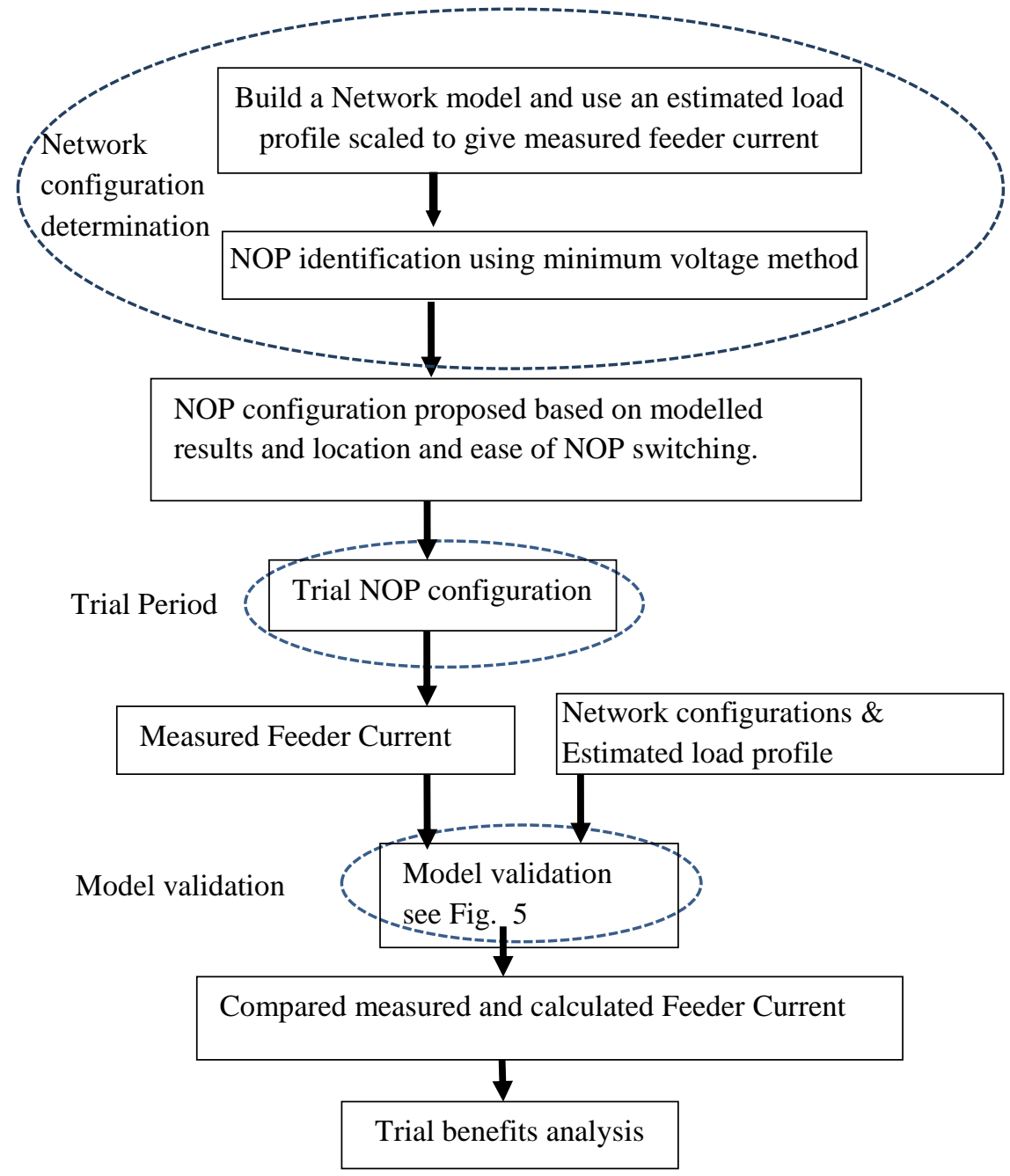

Fig.4 Trial Network showing process of calculating trial benefits 


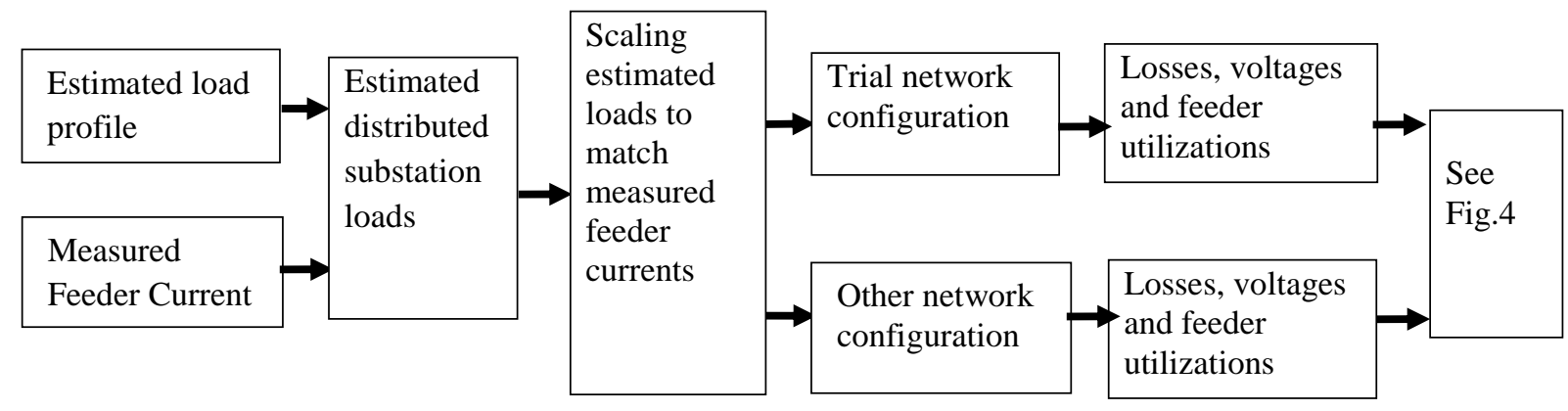

Fig.5 Trial Network showing process of validation through comparison of recorded and calculated feeder data

A key data requirement for load flow analysis of the trial network is quantification of individual substation loads. The individual substation loads cumulatively define the feeder load, and the individual substation loads characterise the distribution of load along a feeder. In reality, it is very rare that measured data for all substation loads on a portion of network exists, so estimates of substation load and how that load varies with time (the load profile) are used within the load flow analysis. Therefore, confidence in projected benefits arising from changes to NOP positions is dependent on the accuracy of estimated load profiles and the resultant distribution of load along feeders.

From this dependency, it follows that the validity of the assumed distribution of load along feeders should be tested to assess the reliance placed on trial results. Table 3 shows key measurements and calculations arising from the trials, where the networks were initially prepared in nominal configuration over the period Week 1. During this period feeder currents are measured (Ref\#1), and from this scaled individual substation loads are calculated (Ref\#5).

Table 3 Key measurements and calculations resulting from the trial

Ref\#1 - measured feeder current (with nominal configuration for week 1 ), based on measured feeder currents

Week 1

Week 2
Ref\#5 - Scaled substation loads (based on estimated sub loads scaled to give a calculated feeder load equal to measured feeder current)
Ref\#2 - Calculated feeder current (based Ref\#5 and feeder config1) 
Ref\#6 scaled loads and nominal configuration) config. 1 for week 2), based on measured feeder currents

Ref\#6 - Scaled substation loads (based on estimated sub loads scaled to give a

calculated feeder load equal to measured feeder current )

A calculated feeder load (Ref\#2) can then be calculated for network configuration 1 associated with time period Week 1, based on the scaled individual substation loads Ref\#5. This calculated feeder current is shown in a greyed cell in Table 3 to indicate that it is a value derived for a configuration that was not actually implemented. For Week 2, a different configuration is actually applied to the network, and the feeder currents are again measured and a feeder load is calculated (Ref\#3). From this a second set of scaled individual substation loads are calculated (Ref\#6). Finally a feeder load for nominal configuration is calculated (Ref\#4) using the second set of scaled substation loads (Ref\#6). Again, this value is shown in a greyed cell in Table 3 to indicate that it is a value derived for a configuration that was not actually implemented

If load could be considered to be constant between the two time periods, then variance of the ratio Ref\#1/Ref\#3 from a value of 1 would indicate a change in losses due to altered network configuration. However, load cannot be assumed to be constant with time, and therefore ratio Ref\#1/Ref\#3 is a function of changed losses due to altered network configuration, and changes in load between periods 1 and 2 .

Ratio Ref\#1/Ref\#4 is related to the change in load, but is also affected by variance between assumed and actual distribution of load along the feeder. Ratio Ref\#2/Ref\#3 is similarly related to change in load and variance between assumed and actual distribution of load along the feeder.

It is therefore postulated that the ratio (Ref\#1/Ref\#4)/( Ref\#2/Ref\#3) will eliminate the effect of time varying load, but will retain an indication of variance between assumed and actual distribution of feeder load. Therefore a value around 1 for the ratio (Ref\#1/Ref\#4)/( Ref\#2/Ref\#3) would indicate no substantial variance between the assumed load distribution of load along the feeder, and the actual distribution of load along the feeder.

\section{Trial Data Analysis}

The two representative networks from the Milton Keynes area (Fig.1 and Fig.2) were used in the trials. The cable network configuration was chosen by comparing the results generated from a modelled typical 24 hour period. Making use of the minimal node voltage algorithm, the optimal configurations for 48 halfhour points based on data from the 15 May 2014 were calculated. The most frequent 8 NOPs were 
identified and recommended as the optimal configuration (referred to as configuration 2). A configuration based on the closest set of practical operating points was specified (referred to as configuration 1), which was applied to the network over a week long period to help with model validation. Hence, the configurations used in this paper are the pre-existing nominal configuration, the closest to the optimal practical configuration 1 and the modelled optimal calculated configuration 2. A similar process was used for the OHL network. The trial configurations used within the FALCON project for Cable and OHL network and corresponding time periods are given in Table 4.

Table 4 Cable and OHL Network Trial dates and associated Network Configurations

\begin{tabular}{lccr}
\hline date & Cable configuration & date & OHL configuration \\
\hline 15-20 May 2014 & Nominal configuration & 01-06 Oct 2014 & Nominal configuration \\
17-24 June 2014 & Configuration 1 & 07-13 Oct 2014 & Configuration 1 \\
\hline
\end{tabular}

Fig. 6 is a plot of the ratio (Ref\#1/Ref\#4)/( Ref\#2/Ref\#3) for the pre-existing nominal NOP configuration and trials configuration 1 . In the chart, the blue trace shows the ratio using our assumed feeder load distribution. From this trace it can be seen that the values varies around 1, indicating no substantial mismatch between assumed load distribution and actual load distribution. If the load is not distributed correctly (evenly or lumped at feeder end), the ratio would be away from 1. Fig. 7 shows an equivalent trace for the OHL network between the pre-existing nominal configuration and optimised practical configuration 1 . 


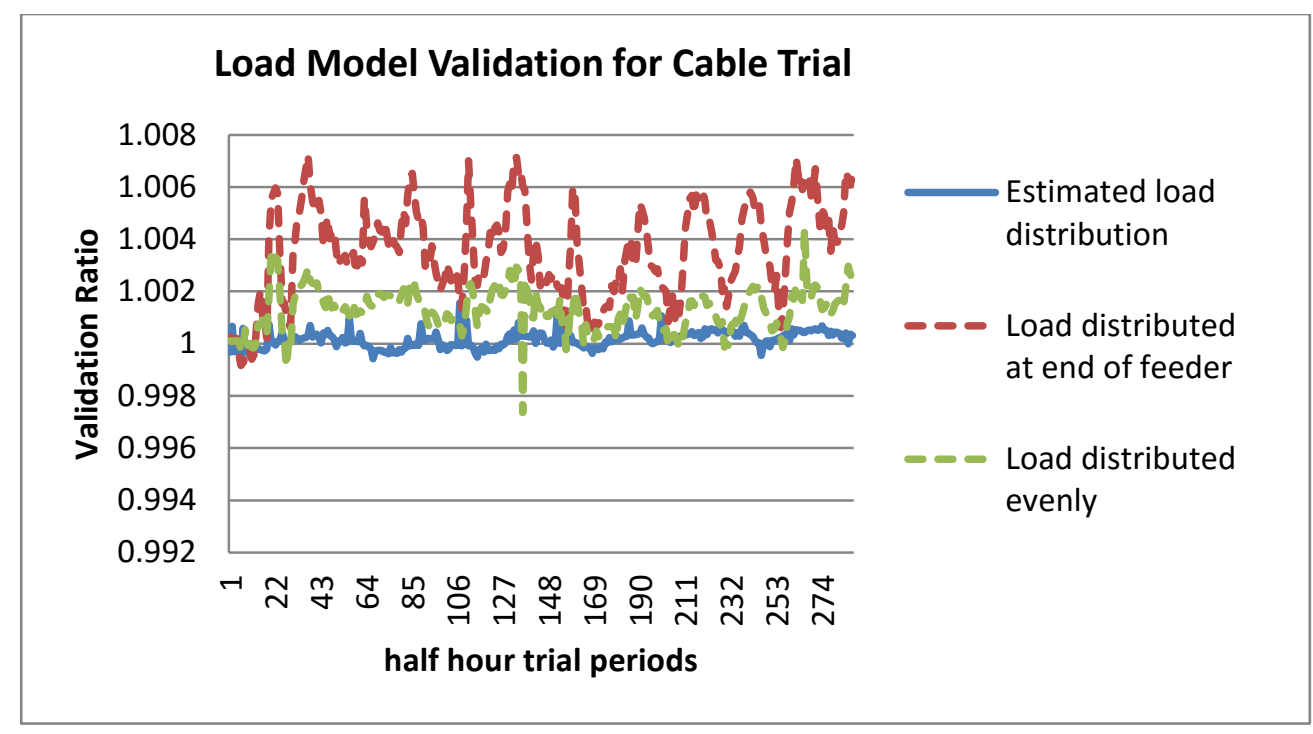

Fig.6 Cable Network ratio (Ref\#1/Ref\#4)/( Ref\#2/Ref\#3) for each half hour slot over trial period



Fig.7 OHL Network ratio (Ref\#1/Ref\#4)/(Ref\#2/Ref\#3) for each half hour slot over trial period

The dotted red trace shows an illustration of the ratio if an alternate load distribution assumption is used (one where the load is substantially biased towards the end of the feeders). This trace does not vary around 1, and shows markedly more variance to load distribution based upon substation load estimates.

Similarly the dotted green trace, illustrates an alternate load distribution assumption (where loads are distributed evenly among the substations), which also does not vary about 1 , and again shows greater variance in value to the assumed load distribution based upon substation load estimates. 
Based upon the above, it is judged that the assumed load distribution used in this paper's analysis, and based upon Falcon substation load estimates, is a satisfactory basis for subsequent modelling for the purpose of outline benefit assessment.

It can be seen that the distribution of load following a change of NOP configuration is an important factor in assessing the impact of a change in network configuration, and therefore the importance of making appropriate load distribution assumptions. In the trial analysis, a statistical model based load profile from WPD was used to distribute the feeder load among substations.

The measured and calculated peak feeder currents over each trial week of the two networks are listed in Table 5 and 6 . Where the measured current is used, a cross check calculated value is listed to ensure total feeder load is correct. The shaded entries show where the current is calculated as opposed to measured.

Table 5 Comparison of calculated and measured peak feeder currents during trial periods for cable network

\begin{tabular}{|c|c|c|c|c|c|c|}
\hline & \multicolumn{2}{|c|}{ Nominal configuration } & \multicolumn{2}{|c|}{ Configuration 1} & \multicolumn{2}{|c|}{ Configuration2 } \\
\hline & $\begin{array}{l}\text { Measured } \\
\text { total feeder } \\
\text { current } \\
\text { (peak) }\end{array}$ & $\begin{array}{l}\text { Calculated } \\
\text { total feeder } \\
\text { current (peak) }\end{array}$ & $\begin{array}{l}\text { Measured total } \\
\text { feeder current } \\
\text { (peak) }\end{array}$ & $\begin{array}{l}\text { Calculated total } \\
\text { feeder current } \\
\text { (peak) }\end{array}$ & $\begin{array}{l}\text { Measured total } \\
\text { feeder current } \\
\text { (peak) }\end{array}$ & $\begin{array}{l}\text { Calculated total } \\
\text { feeder current } \\
\text { (peak) }\end{array}$ \\
\hline $\begin{array}{l}\text { Week } 1 \\
\text { Week } 2\end{array}$ & $\begin{array}{l}633 \\
-\end{array}$ & $\begin{array}{l}633 \\
646\end{array}$ & $\begin{array}{l}- \\
646\end{array}$ & $\begin{array}{l}632 \\
646\end{array}$ & $\begin{array}{l}- \\
-\end{array}$ & $\begin{array}{l}632 \\
646\end{array}$ \\
\hline & \multicolumn{2}{|c|}{ Nominal configuration } & \multicolumn{2}{|c|}{ Configuration 1} & \multicolumn{2}{|c|}{ Configuration 2} \\
\hline & $\begin{array}{l}\text { Measured } \\
\text { total feeder } \\
\text { current } \\
\text { (peak) }\end{array}$ & $\begin{array}{l}\text { Calculated } \\
\text { total feeder } \\
\text { current (peak) }\end{array}$ & $\begin{array}{l}\text { Measured total } \\
\text { feeder current } \\
\text { (peak) }\end{array}$ & $\begin{array}{l}\text { Calculated total } \\
\text { feeder current } \\
\text { (peak) }\end{array}$ & $\begin{array}{l}\text { Measured total } \\
\text { feeder current } \\
\text { (peak) }\end{array}$ & $\begin{array}{l}\text { Calculated total } \\
\text { feeder current } \\
\text { (peak) }\end{array}$ \\
\hline Week 1 & 376 & 376 & - & 374 & - & 374 \\
\hline Week 2 & - & 395 & 393 & 393 & - & 391 \\
\hline
\end{tabular}

In each trial period, the calculated feeder current varies slightly with the NOP configuration because the loss varies. The total load is set to be identical between the modelled configurations while the ratio of the total calculated feeder currents is consistent across the three configurations. If the load distribution or model has been inaccurate then the ratio of calculated total feeder current would have been inconsistent 
indicating an inaccuracy in load distribution. The increase in feeder current in June highlights the complexity of this type of analysis because the total load current has increased compared to previous weeks in the trial.

\section{Trial Benefit Analysis}

The section compares calculated spare feeder capacity, power loss and minimal node voltage under the different configurations from section 5. The load distribution calculated above is used and the calculation results are compared among the different configuration during the trials periods.

Table 7 shows the sum of losses in the trial periods for cable network. The highest losses can be found with the nominal configuration. The losses can be reduced with configuration 1. Calculation results show the potential losses reduction that could be achieved by the recommended configuration (configuration 2). Table 8 shows the same analysis for the OHL Network with a similar reduction in losses.

Table 7 Comparison of calculated total losses of cable network with configurations in trial periods (MWh)

\begin{tabular}{lccc}
\hline & Nominal configuration & Configuration 1 & Configuration2 \\
\hline & & & \\
Week 1 & 3.7 & 3.4 & 3.4 \\
Week 2 & 5.1 & 4.7 & 4.5 \\
\hline
\end{tabular}

Table 8 Comparison of calculated total losses of OHL network with configurations in trial periods (MWh)

\begin{tabular}{lccc}
\hline & Nominal configuration & Configuration 1 & Configuration2 \\
\hline Week 1 & 4.7 & 4.1 & 4.1 \\
Week 2 & 5.2 & 4.6 & 4.6 \\
\hline
\end{tabular}

The simulation results in Table 9 and 10 show the \% highest feeder utilisation for each network. The higher this value the less available headroom capacity there is in the feeder. There is scope to improve the network capacity by around 7 to $10 \%$ by changing the position of the NOP's. 
Table 9 Comparison of feeder utilisation of cable network with configurations in trial periods (\%)

\begin{tabular}{lccc}
\hline & Nominal configuration & Configuration 1 & Configuration2 \\
\hline & & & \\
Week 1 & 45 & 39 & 37 \\
Week 2 & 51 & 41 & 43 \\
\hline
\end{tabular}

Table 10 Comparison of feeder utilisation of OHL network with configurations in trial periods (\%)

\begin{tabular}{lccc}
\hline & Nominal configuration & Configuration 1 & Configuration2 \\
\hline & & & \\
Week 1 & 36 & 39 & 39 \\
Week 2 & 39 & 42 & 42 \\
\hline
\end{tabular}

Table 11 and Table 12 show the calculated minimal node voltage for the pre-existing nominal configuration and practical optimal configurations of the cable and OHL networks respectively. It should be noted that the calculated voltages are based on the actual measured total feeder loads in that period, and the assumed distribution of load along the feeders. It is important to recognise that the voltages would be different if the actual distribution of loads along the feeders were not as assumed. The voltage at the primary substations is set to $11.3 \mathrm{kV}$. Magnitude of minimal voltages for the grey shaded cells can be calculated, but use further modelling assumptions. There is no significant change in voltage on the cable network. However, there are notable improvements on the OHL network as shown in Table 12.

Table 11 Comparison of minimum voltages of cable network with configurations in trial periods $(\mathrm{kV})$

\begin{tabular}{lccc}
\hline & Nominal configuration & Configuration 1 & Configuration2 \\
\hline Week 1 & 11.17 & 11.17 & 11.18 \\
Week 2 & 11.19 & 11.19 & 11.20 \\
\hline
\end{tabular}


Table 12 Comparison of minimum voltages of OHL network with configurations in trial periods $(\mathrm{kV})$

\begin{tabular}{lrrr} 
Week 1 & 10.89 & 10.93 & 10.95 \\
& & & 10.86 \\
Week 2 & 10.83 & 10.86 & 10.85 \\
\hline
\end{tabular}

Fig.8 shows percentage utilisation of feeder pairs with pre-existing nominal and preferred NOP configurations of Cable network over trial week1 $\left(15^{\text {th }}-20^{\text {th }}\right.$ May 2014) under the loss minimisation method. Adjusting the open point position allows load to be transferred from Marlborough Street Way 07 (MS07) to Newport Pagnell Way 08 (NP08) with the result that the skew in feeder utilisation (away from line of balanced load between feeders - dashed line) decreases and the percentage utilisation on Marlborough Street Way 07 reduces by around 12\% over week1. Meanwhile, the utilisation on Newport Pagnell Way 08 increases about $1 \%$. It is clear that the feeder pair is more balanced with the preferred configuration.

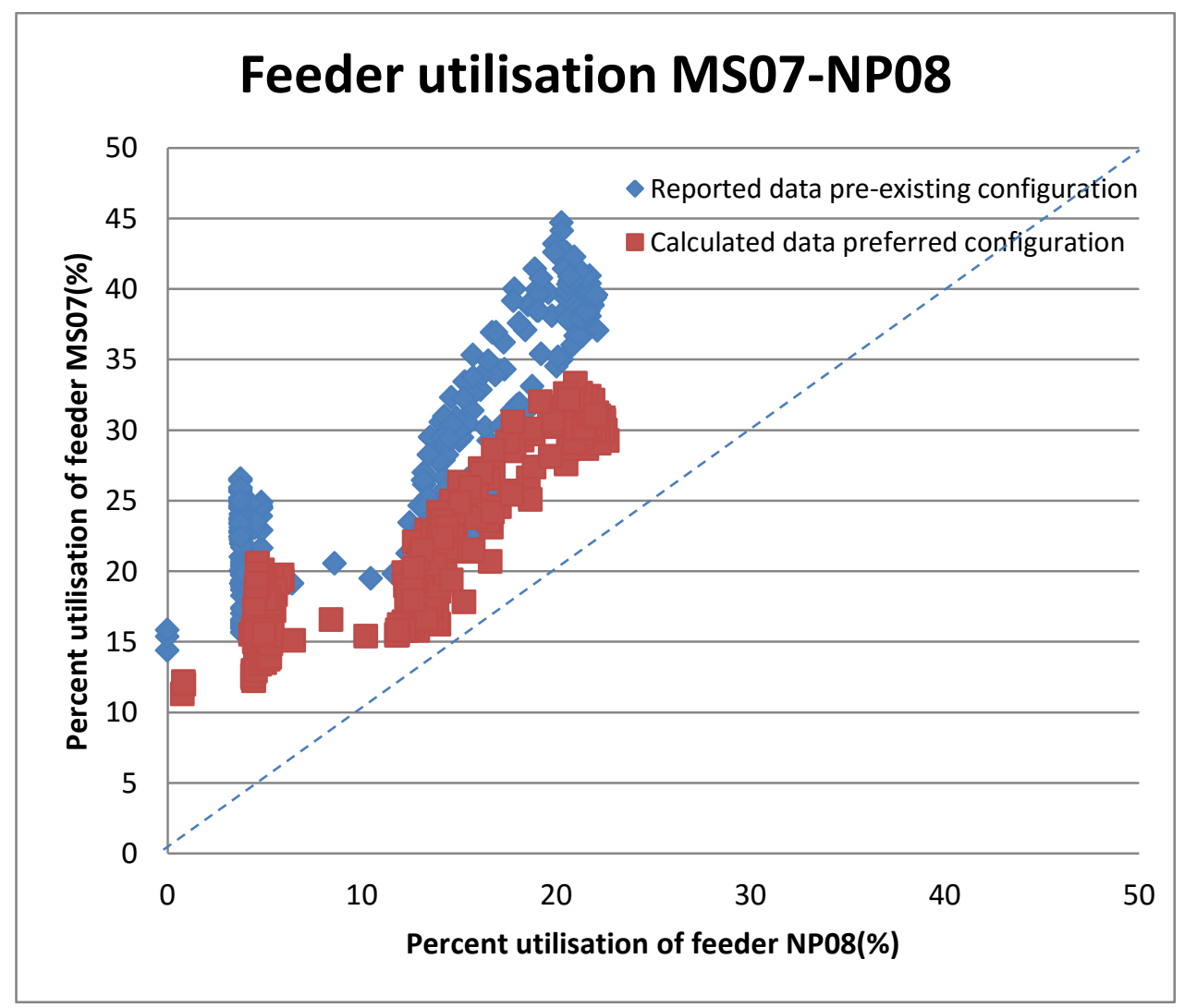

Fig. 8 Comparison of feeder utilisation during week 1 (15-20May 2014) with nominal configuration measured (blue diamond) and configuration 1 (red squares) calculated 
Fig.9 shows percentage utilisation of feeder pairs with pre-existing nominal and preferred practical NOP configurations over trial week $1\left(1^{\text {st }}-6^{\text {th }}\right.$ Oct 2014$)$ under the loss minimisation method. The similarity in the reported feeder loading with the calculated feeder loadings for each of the trial weeks under different configurations is replicated across all the feeder pairs.

Referring to Fig.9 in the pre-existing configuration, the maximum percentage feeder utilisation of Newton Rd Way 05 (NR05) is around 24\% (pre-existing configuration shown as blue line in both figures). Adjusting the open point position causes load to be transferred from Newton Road way 05 to Winslow Way 03 (WS03), and as a result, peak utilisation of NR05 falls to around 19\%.

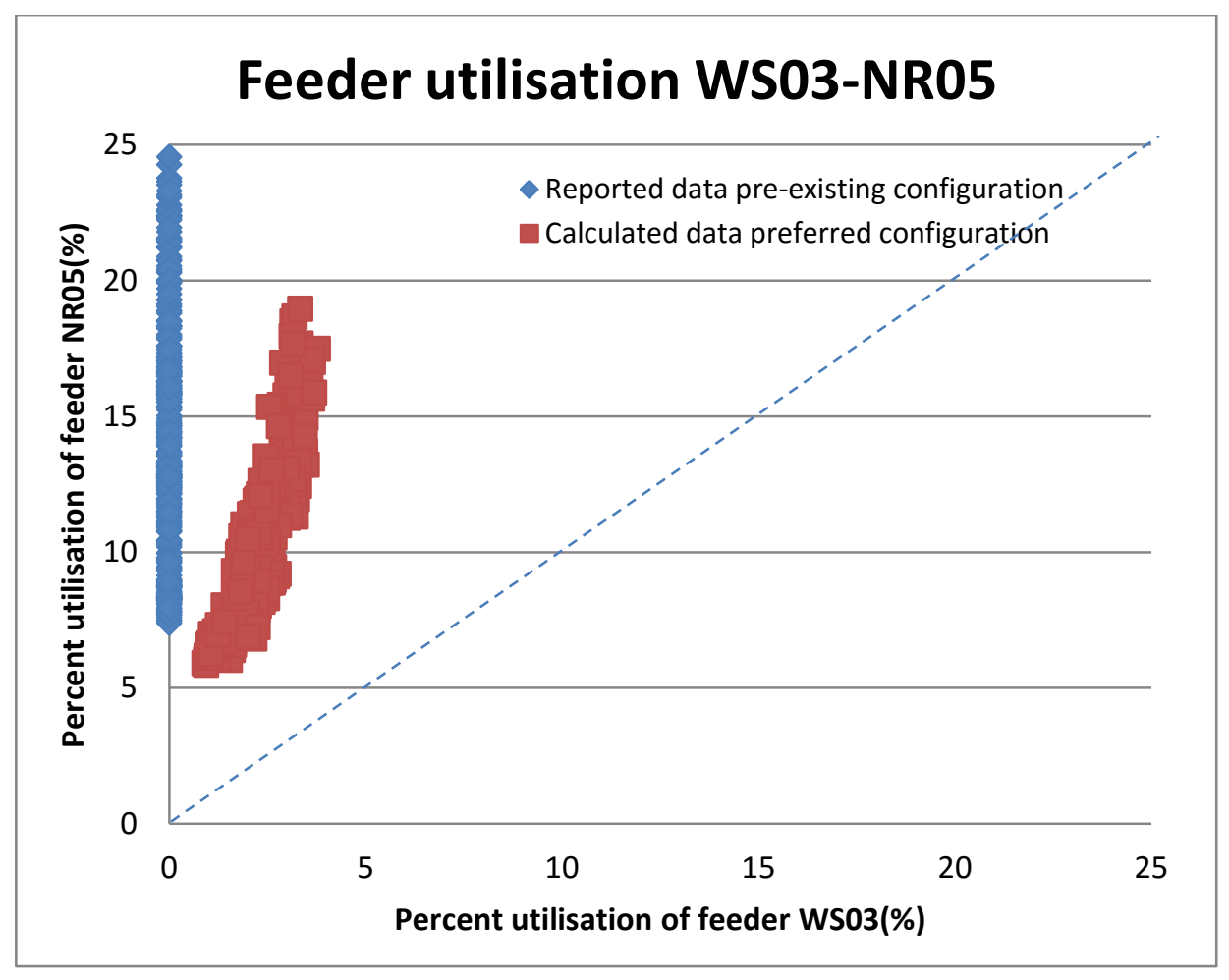

Fig. 9 Comparison of feeder utilisation during week 1 (01-06Oct 2014) with nominal configuration measured (blue diamond) and configuration 1 (red squares) calculated

The process of finding the NOP indicates that benefits in network headroom and loss reduction are available for the dates analysed on the Cable network. However only an improvement in losses is available on the OHL network- in this case this is because the analyse concentrates on voltage improvement. An issue with this network is that one of the feeders has a much lower capacity than the other feeders and there is no mechanism in the present approach for taking this into account. These improvements can be realised by permanently moving the NOP. Moving the NOP within a $24 \mathrm{hr}$ period may generate some additional benefit but at a cost relating to switch gear life span and greater operational complexity. 


\section{Conclusion}

Confidence in the benefits from network reconfiguration is dependent on the accuracy of estimated time-varying loads. This research firstly focuses on determining a network configuration and then testing this configuration to see if the benefits may be quantified in the presence of uncertain load. This paper looks at a method of calculating the network configuration at different loads using different methods and the associated benefits. There are trade-offs around any method whether it be heuristic or otherwise routine and the decision was made to trade number of customers along a feeder in favor of reducing losses. The minimum voltage method was used to set up a set of different network configurations.

During the model validation, the feeder currents are distributed among the substations according to the estimated load profile. The loads are scaled to match the individual calculated feeder currents with the measured ones. The proposed load validation method can eliminate the effect of time varying load and retain the indication of variance between assumed and actual distribution of feeder load. The validation show that load distribution and estimation in FALCON is reasonable for benefit assessment.

In conclusion, it is difficult to validate network reconfiguration especially relating to advantages pertaining to loss reduction in light of varying and estimated loads. This paper presents a method of undertaking such an analysis by comparing measured and calculated data under different network configurations. The proposed load validation method can secure the confident on benefit assessment for the industrial application.

\section{Acknowledgments}

The authors would like to acknowledge the help of employees of Western Power Distribution who made this research possible through their hard work in implemention and data collection as part of the LCNF funded FALCON project.

\section{References}

[1] Ofgem, Low Carbon Networks Fund, [Online]. Available: https://www.ofgem.gov.uk/electricity/ distributionnetworks/network-innovation/low-carbon-networks-fund, (accessed Feb. 2014).

[2] Western Power Distribution, FALCON, [Online]. Available: http://westernpowerinnovation.co.uk/ Falcon.aspx, (accessed Feb. 2014).

[3] M. Narimani, A Vahed, R Azizipanah, M. Javidsharifi. :'Enhanced gravitational search algorithm for multiobjective distribution feeder reconfiguration considering reliability, loss and operational cost', IET. Gener. Transm. and Distrib., 2014, 8, (1), pp. 55-69

[4] D.Bernardon., V. Garcia, A. Ferreira, L.Canha.:'Multicriteria distribution network reconfiguration considering subtransmission analysis', IEEE Trans. Power Deliv., 2010, 25,(4), pp. 2684-2691 
[5] L. Guedes, A. Lisboa, D. Vieira, R. Saldanha.:'A multi-objective heuristic for reconfiguration of the electrical radial network', IEEE Trans. Power Deliv., 2013, 28, (1), pp. 311-319

[6] A. Malekpour, T. Niknam, A. Pahwa, A. Fard.: 'Multi-objective stochastic distribution feeder reconfiguration in systems with wind power generators and fuel cells using the point estimate method', IEEE Trans. Power Syst., 2013, 28, (2), pp. 1483-1492

[7] T. Niknam, A. Kavousifard, J.Aghaei.:'Scenario-based multi-objective distribution feeder reconfiguration considering wind power using adaptive modified particle swarm optimisation', IET. Renew Power Gener., 2012, 6, (4), pp. 236-247

[8] B. Amanulla, S. Chakrabarti, S.N. Singh. :'Reconfiguration of power distribution systems considering reliability and power loss', IEEE Trans. Power Deliv., 2012, 27, (2), pp. 918-926

[9] I. Song, W. Jung, J. Kim, S. Yun, J. Choi, S. Ahn.: 'Operation schemes of smart distribution networks with distributed energy resources for loss reduction and service restoration', IEEE Trans. Smart Grid., 2013, 4, (1), pp. 367-374

[10] M, Tsai, F.Hsu.:"Application of grey correlation analysis in evolutionary programming for distribution system feeder reconfiguration', IEEE Trans. Power Syst., 2010, 25, (2), pp. 1126-1133

[11] A. Botea, J. Rintanen, D. Banerjee.: 'Optimal reconfiguration for supply restoration with informed A* search', IEEE Trans. Smart Grid., 2012, 3, (2), pp. 583-593

[12] A. Menders, N. Boland, P. Guiney, C. Riveros.: 'Switch and tap-changer reconfiguration of distribution network using evolutionary algorithms', IEEE Trans. Power Syst., 2013, 28, (1), pp. 85-92

[13] R. Jabr, R. Singh, B.C. Pal, "Minimum loss network reconfiguration using mixed-integer convex programming", IEEE Trans, Power Syst., 2012, 27, (2), pp. 1106-1115

[14] A. Gonzalez, F. Echavarren, L. Rouco, T. Gomez.:"A sensitivities computation method for reconfiguration of radial networks', IEEE Trans. Power Syst., 2012, 27, (3), pp. 1294-1301

[15] C. Ababei, R. Kavasseri.: 'Efficient network reconfiguration using minimum cost maximum flow-based branch exchanges and random walks-based loss estimations', IEEE Trans. Power Syst., 2011, 26, (1), pp. 30-37

[16] A. Asuhaimi, A. Khorasani, A. Khairuddin, M. Naeini.:'Reconfiguration of radial electrical network through minimum-current circular-updating-mechanism method', IEEE Trans. Power Syst., 2012, 27, (2), pp. 968-974

[17] A. Asuhaimi, A. Ferdavani, A. Khairuddin, M. Naeini.: 'Two circular-updating hybrid heuristic methods for minimum-loss reconfiguration of electrical distribution network', IEEE Trans. Power Syst., 2013, 28, (2), pp. $1318-1323$

[18] A. Ferdavani, A. Zin, A. Khairuddin, M. Naeini.: 'Reconfiguration of distribution system through two minimum-current neighbour-chain updating methods', IET. Renew Power Gener., 2013, 7, (12), pp. 1492-1497

[19] M. O. Leonardo, Q. Lyra.: 'Adaptive hybrid genetic algorithm for technical loss reduction in distribution networks under variable demands', IEEE Trans. Power Syst., 2009, 24,(1), pp. 445-453 
[20] A. Merlin, H. Back, "Search for a minimal-loss operation spanning tree configuration in an urban power distribution system". Proc of PSCC $5^{\text {th }}$ Power System Computation Conference, Cambridge (UK), 1975

[21] D. Shimohammadi, H. Hong, "Reconfiguration of electric distribution networks for resistive line losses reduction" IEEE Press, 1989

[22] S.Civanlar, J.J.Grainger, H.Yin and S.S.H.Lee, "Distribution feeder reconfiguration for loss reduction" IEEE Trans. Power Deliv, 1988, 3,(1), pp. 1217-1223

[23] M.Baran, F. Wu, "Network reconfiguration in distribution systems for loss reduction and load balancing", IEEE Trans. Power Deliv, 1989, 4, (3), pp.1401-1407, 1989

[24] A. Kavousi-Fard, T. Niknam.: 'Optimal distribution feeder reconfiguration for reliability improvement considering uncertainty', IEEE Trans. Power Deliv., 2014, 29, (3), pp. 1344-1353

[25] S, Yin.,C, Lu.: 'Distribution feeder scheduling considering variable load profile and outage costs', IEEE Trans. Power Syst., 2009, 24, (2), pp. 652-660

[26] C. Su.: 'Stochastic evaluation of voltage in distribution network with distributed generation using detailed distribution operation models', IEEE Trans. Power Syst., 2010, 25, (2), pp. 786-795

[27] F. Vinicius, L Carmen.: 'Active distribution network integrated planning incorporating distributed generation and load response uncertainties', IEEE Trans. Power Syst., 2011, 26, (4), pp. 2164-2172 